This brings us back to our titular question derived from Shakespeare: Would a rose by any other name really smell as sweet? We believe the answer is no-our language and framing matter. Being thoughtful in our communication ensures that we are including all our stakeholders, accurately framing our work in a positive light, and correctly describing the work we do-all are critical components of our work in infection prevention.

Financial support. No financial support was provided relevant to this article.

Potential conflicts of interest. All authors report no conflicts of interest relevant to this article.

\section{References}

1. Abadi M. Democrats and Republicans speak different languages—and it helps explain why we're so divided. Business Insider website. http://www. businessinsider.com/political-language-rhetoric-framing-messaging-lakoffluntz-2017-8. Published August 2017. Accessed February 19, 2018.

2. Chapman S. Other people's smoke: What's in a name? Tobacco Control 2003;12:113-114.

3. Stewart $\mathrm{AE}$, Lord $\mathrm{JH}$. Motor vehicle crash versus accident: a change in terminology is necessary. J Trauma Stress 2002;15:333-335.

4. Richtel M. It's no accident: advocates want to speak of car 'crashes' instead. The New York Times website. https://www.nytimes.com/2016/05/23/ science/its-no-accident-advocates-want-to-speak-of-car-crashes-instead. html. Published May 22, 2016. Accessed April 2, 2018.

\title{
Promoting an action plan for devices in the emergency department-does it impact catheter duration?
}

\author{
Bernard Surial MD ${ }^{1,2}$, Andrew Atkinson ${ }^{1}$, Susanne Nüesch $\mathrm{MD}^{3}$, Joerg C. Schefold MD ${ }^{4}$ and Jonas Marschall MD \\ ${ }^{1}$ Department of Infectious Diseases, Inselspital, Bern University Hospital, University of Bern, Switzerland, ${ }^{2}$ Department of Internal Medicine, Inselspital, Bern \\ University Hospital, University of Bern, Switzerland, ${ }^{3}$ Department of Emergency Medicine, Inselspital, Bern University Hospital, University of Bern, Switzerland \\ and ${ }^{4}$ Department of Intensive Care Medicine, Inselspital, Bern University Hospital, University of Bern, Switzerland
}

To the Editor-Urinary catheters, arterial lines, and central venous catheters (CVCs) are frequently placed in emergency departments (EDs). However, because many devices are inserted for inappropriate and poorly documented reasons, ${ }^{1,2}$ physicians on the receiving hospital floors are often unaware of their presence and indication, which can lead to unnecessarily long catheterization. ${ }^{3}$ We hypothesized that if the indication and anticipated duration were explicitly stated in the ED discharge report, subsequent care providers would be more aware of these devices in place and could decide more confidently whether to remove them. This information could increase appropriate use, shorten the duration of catheterization, and thereby reduce device-associated complications.

We conducted an intervention study in a 950-bed university hospital in Switzerland, where we included all patients admitted to the hospital with a device (ie, urinary catheter, arterial line, or CVC) placed in our 30-bed ED. Patients with devices placed before ED arrival and patients transferred to another hospital were excluded. We captured data during a preintervention period (July 2016-March 2017) and an intervention period (April-June 2017). Because this study was part of a quality improvement project, no institutional review board approval was required.

During the intervention period, all ED physicians were asked to include in the ED discharge report an action plan for each inserted device with (1) the type of device, (2) the indication for its placement, (3) the anticipated duration. Our infection prevention team held a meeting at the beginning of the intervention, posted indication sheets in the ED work area, and sent weekly e-mail reminders with pertinent information. The timing of this

Author for correspondence: Bernard Surial, MD, Department of Infectious Diseases, Inselspital, Bern University Hospital, Freiburgstrasse 18, CH-3010 Bern, Switzerland. E-mail: Benard.Surial@insel.ch

Cite this article: Surial B, et al. (2018). Promoting an action plan for devices in the emergency department-does it impact catheter duration? Infection Control \& Hospital Epidemiology 2018, 39, 1011-1012. doi: 10.1017/ice.2018.132 period was aligned with the baseline surveillance of a national pilot program aimed at reducing urinary catheter utilization and its complications with bundled interventions. ${ }^{4}$

The primary outcome was duration of device placement before and after the intervention. Secondary outcomes were device insertion rates and compliance with the intervention requirements. Electronic health records were used to identify eligible patients and to obtain demographic data including time of device placement and removal. All ED discharge reports during the intervention period were reviewed to determine whether a device-related action plan was proposed. Continuous data are presented as median (interquartile range, IQR), and categorical data are presented as numbers and percentages. We compared continuous variables using the Wilcoxon rank-sum and Kruskal-Wallis tests and proportions using the $\chi^{2}$ test. Data analyses were performed using R Studio software. ${ }^{5}$

During the study period, 1,346 devices were inserted in ED patients admitted to our hospital. Most were urinary catheters $(\mathrm{n}=771,57.3 \%)$ and arterial lines $(\mathrm{n}=528,39.2 \%)$, and a few were CVCs $(n=47,3.5 \%)$. Most patients were male $(n=805$, $59.8 \%$ ) with a median age of 70 years (IQR, 55.0-79.0) and were admitted to the intensive care unit at some point during their hospitalization $(n=979,72.7 \%)$. Table 1 summarizes the catheter durations and their insertion rates. The median duration of urinary catheters was 70.2 hours (35.7-138.0); the median duration of arterial lines was 40.2 hours (20.6-75.4); and the median duration of CVC was 78.8 hours (25.5-163.5). Neither overall duration of catheterization nor that of individual devices decreased over time.

A device was placed in $10.2 \%$ of all admitted ED patients. Urinary catheters were placed in $5.9 \%$, followed by arterial lines in $4.0 \%$, and $\mathrm{CVC}$ in $0.4 \%$ of all patients. Although the overall insertion rates did not change after the intervention, we observed increased use of arterial lines in the intervention period $(P=.01)$. During the intervention period, devices were mentioned in 102 ED discharge reports (29.6\%); a complete action plan was present in 35 cases $(10.1 \%)$. The median duration of devices with an 
Table 1. Duration of Catheterization and Insertion Rates of Devices Placed in the Emergency Department

\begin{tabular}{lccc}
\hline & $\begin{array}{c}\text { Preintervention } \\
(\mathrm{n}=1,001)\end{array}$ & $\begin{array}{c}\text { Intervention } \\
(\mathrm{n}=345)\end{array}$ & $P$ Value ${ }^{\mathrm{a}}$ \\
\hline \multicolumn{4}{l}{ Duration of catheterization, median $\mathrm{h}(\mathrm{IQR})$} \\
\hline All devices $(\mathrm{n}=1,346)$ & $57.5(27.2-116.3)$ & $48.2(24.1-107.4)$ & .11 \\
\hline Urinary catheter $(\mathrm{n}=771)$ & $70.5(36.7-140.3)$ & $67.1(32.0-127.1)$ & .18 \\
\hline Arterial line $(\mathrm{n}=528)$ & $39.3(20.3-74.1)$ & $41.9(22.6-86.0)$ & .51 \\
\hline CVC $(\mathrm{n}=47)$ & $99.8(48.1-169.6)$ & $36.9(24.1-108.5)$ & .15 \\
\hline Insertion rates, no. (\% of all hospitalized patients) & \\
\hline Hospitalized ED patients & $9,884(100)$ & $3,250(100)$ & \\
\hline All devices & $1,001(10.1)$ & $345(10.6)$ & .45 \\
\hline Urinary catheter & $596(6.0)$ & $175(5.4)$ & .19 \\
\hline Arterial line & $372(3.8)$ & $156(4.8)$ & .01 \\
\hline CVC & $33(0.3)$ & $14(0.4)$ & .53 \\
\hline
\end{tabular}

NOTE. CVC, central venous catheter; ED, emergency department.

${ }^{a}$ Wilcoxon or $\chi^{2}$ test.

action plan was 73.0 hours and did not differ significantly between these periods $(P=.45)$. A sensitivity analysis with 2 preintervention periods (period 1: July-December 2016; period 2: January-March 2017) did not reveal seasonality, and its results did not differ substantially from the primary analysis (data not shown).

In this intervention study aimed to reduce duration of catheterization through improved documentation, just one-third of all devices were mentioned in the ED discharge reports, and action plans were present in only $10 \%$ of cases. We observed no decrease in the duration of catheterization or insertion rates after our intervention, even if we analyzed only those devices with an action plan. Unexpectedly, we noted increased use of arterial lines over time, suggesting some variation in severity of illness between the 2 periods. The documentation rate achieved in this study was similar to the $22 \%$ reported in another study on urinary catheters in the ED. ${ }^{2}$

In addition, both duration of urinary catheterization and insertion rates are in agreement with previously published results. ${ }^{1,6,7}$

The low uptake of documentation, a limitation of this study, might reflect difficulties implementing preventive measures in the ED. Emergency physicians act in busy environments with multiple shifts and patient handovers where infection prevention efforts are not necessarily a priority. Additionally, awareness of device-associated complications may be low because they usually develop after discharge from the ED. Incorporating mandatory fields into the electronic medical record specifying indication and estimated duration might have improved the intervention uptake, but this option was not available.

In our institution, ED discharge reports remain the most important form of communication between the ED and admitting hospital floors. Although improved documentation neither reduced utilization nor duration of catheterization in this study, it reinforces physician involvement in placement decisions and should therefore be promoted.

In conclusion, recommending an action plan in the ED discharge report appears insufficient for reducing device utilization. Implementing other measures, such as mandatory device plans or daily device rounds, may be more promising.

Acknowledgments. The authors thank Caspar Breitenstein and Barbara Schärer for their assistance with data extraction.

Financial support. No financial support was provided relevant to this article.

Potential conflicts of interest. All authors report no conflicts of interest relevant to this article.

\section{References}

1. Schuur JD, Chambers JG, Hou PC. Urinary catheter use and appropriateness in US emergency departments, 1995-2010. Acad Emerg Med 2014; 21:292-300.

2. Gokula RM, Smith MA, Hickner J. Emergency room staff education and use of a urinary catheter indication sheet improves appropriate use of foley catheters. Am J Infect Control 2007;35:589-593.

3. Saint S, Wiese J, Amory JK, et al. Are physicians aware of which of their patients have indwelling urinary catheters? Am J Med 2000;109:476-480.

4. progress! Sicherheit bei Blasenkathetern, Patient Safety Switzerland website. http://www.patientensicherheit.ch/dms/Progress-Programme/progress-_Blasen katheter/Synopsis_20160426.pdf. Published 2016. Accessed April 28, 2018.

5. R Studio software website. https://www.rstudio.com. Accessed April 28, 2018.

6. Gokula RR, Hickner JA, Smith MA. Inappropriate use of urinary catheters in elderly patients at a midwestern community teaching hospital. Am J Infect Control 2004;32:196-199.

7. Greene MT, Fakih MG, Watson SR, Ratz D, Saint S. Reducing inappropriate urinary catheter use in the emergency department: comparing two collaborative structures. Infect Control Hosp Epidemiol 2017:1-8. 